\title{
Management of life-threatening calcium channel blocker overdose with continuous veno-venous hemodiafiltration with charcoal hemoperfusion
}

\author{
Suneel K. Garg, Pankaj K. Goyal, Rahul Kumar, Deven Juneja, Alka Bhasin, Omender Singh
}

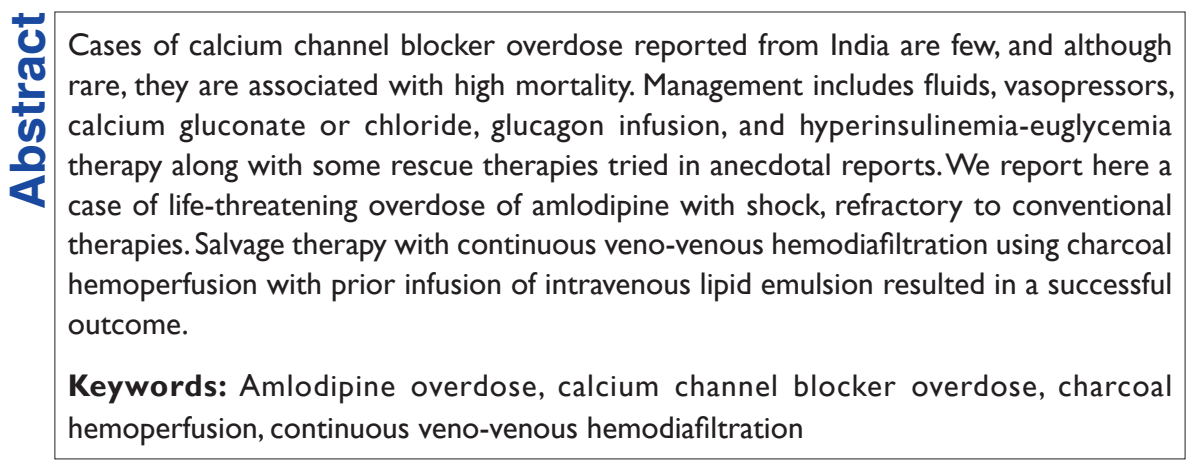

\begin{tabular}{|l|}
\hline Access this article online \\
\hline Website: www.ijccm.org \\
\hline DOI: 10.4103/0972-5229.133939 \\
\hline Quick Response Code: \\
\hline \\
\hline
\end{tabular}

\section{Introduction}

Calcium channel blockers (CCB) are the leading cause of cardiovascular drug overdose ${ }^{[1]}$ Complications such as hypotension, pulmonary edema, and conduction blocks are responsible for adverse outcomes. Reports of CCB overdose are scarce in Indian literature. ${ }^{[2,3]}$ We describe here a case of life-threatening overdose of amlodipine causing shock refractory to standard management.

\section{Case Report}

The case we present here is about a 42-year-old male, who was hypertensive (on amlodipine $5 \mathrm{mg}$ bd), with history of left hemiglossectomy and modified radical neck dissection for carcinoma tongue, a renal transplant recipient (on triple dose immunosuppression), and hepatitis $C$ virus positive status was admitted with an alleged history of consumption of 100 tablets of amlodipine (5 $\mathrm{mg}$ each, total dose $500 \mathrm{mg}$ ) around $5 \mathrm{~h}$

\section{From:}

Institute of Critical Care Medicine, Max Super Speciality Hospital, New Delhi, India

\section{Correspondence:}

Dr. Deven Juneja, Institute of Critical Care Medicine, Max Super Speciality Hospital, 1, Press Enclave Road, Saket, New Delhi - 110 017, India.

E-mail: devenjuneja@gmail.com prior to presentation. On admission, he was drowsy but was responding to painful stimuli. His heart rate was 52/ min, blood pressure was $40 \mathrm{mmHg}$ systolic, respiratory rate was $8 / \mathrm{min}$ and was afebrile. Systemic examination was within the normal limits. He was intubated electively, given fluid boluses and started on dopamine and noradrenaline infusions. His blood gases showed acute respiratory and metabolic acidosis with hyperlactatemia (4.5 mmol/1). A 12-lead electrocardiograph was normal. Gastric lavage was done with $100 \mathrm{~g}$ of charcoal. He was given $3 \mathrm{~g}$ IV calcium gluconate as a slow bolus followed by $50 \mathrm{mg} / \mathrm{h}$ infusion along with $5 \mathrm{mg}$ IV glucagon over $15 \mathrm{~min}$ followed by an infusion at $5 \mathrm{mg} / \mathrm{h}$. He was also started on injection insulin and 50\% dextrose as hyperinsulinemia-euglycemia therapy.

His condition continued to deteriorate, despite aggressive resuscitation. Terlipressin infusion at 2-3 $\mu \mathrm{g} / \mathrm{min}$ was also started along with injection hydrocortisone $100 \mathrm{mg}$ tds as an immunosuppressant as the patient was postrenal transplant recipient. Mean arterial pressure (MAP) could not be maintained more than $50 \mathrm{mmHg}$ despite very high doses of vasopressors (dopamine $20 \mu \mathrm{g} / \mathrm{kg} / \mathrm{min}$, norepinephrine $20 \mu \mathrm{g} / \mathrm{min}$, epinephrine $20 \mu \mathrm{g} / \mathrm{min}$ and terlipressin $10 \mu \mathrm{g} / \mathrm{min})$. In view of refractory shock and 
anuria, with severe metabolic acidosis, continuous veno-venous hemodiafiltration (CVVHDF) with charcoal hemoperfusion using HA Resin hemoperfusion cartridge (Model HA 280, Jafron Biomedical Co., Ltd.) along with $250 \mathrm{ml}$ of $20 \%$ intravenous (IV) lipid emulsion given prior to CVVHDF was started as rescue therapy [Figure 1].

The patient's condition started improving with increase in MAP around $6 \mathrm{~h}$ after starting CVVHDF. Another session of CVVHDF with charcoal hemoperfusion with IV lipid emulsion was given after $24 \mathrm{~h}$. Vasopressors were progressively weaned off in the next $96 \mathrm{~h}$ and stopped on day 7 . The infusions of glucagon, calcium and insulin-dextrose were continued for $96 \mathrm{~h}$ and then gradually stopped. CVVHDF without charcoal hemoperfusion was stopped on day 12 as patient's renal functions started improving. Total dose of glucagon used was $252 \mathrm{mg}$, calcium gluconate was $64 \mathrm{~g}$ and insulin was 2000 IU. The patient was extubated on day 11 and transferred to wards on day 13.

\section{Discussion}

Amlodipine is a CCB of dihydropyridine class and is prescribed for the treatment of hypertension, angina pectoris and congestive heart failure. ${ }^{[4]}$ It has predominant effect on vascular smooth muscle cellas and causes marked peripheral vasodilatation and hypotension although it also causes coronary vasodilation. ${ }^{[4]}$ It is fully absorbed from the gastrointestinal tract with peak plasma levels reaching in 6-12 $\mathrm{h}$, has a large volume of distribution and is extensively distributed in tissues and organs. The drug is highly lipophilic with $97.5 \%$ being protein bound. It undergoes extensive hepatic metabolism to inactive metabolites with a mean elimination half-life of 35-50 h. ${ }^{[5]}$

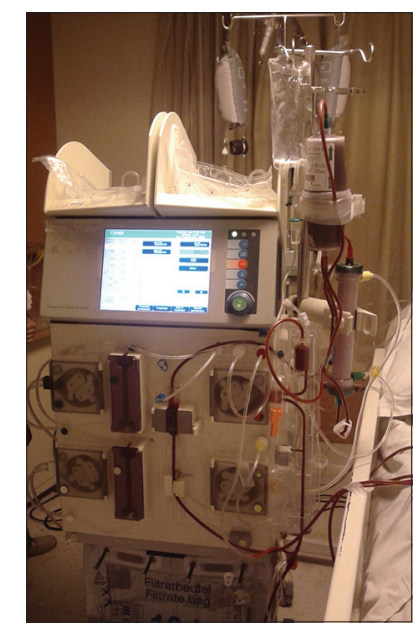

Figure I: Continuous veno-venous hemodiafiltration using HA Resin Hemoperfusion Cartridge (Model HA 280, Jafron Biomedical Co., Ltd.)
Physical symptoms of amlodipine overdose are nonspecific such as headache, nausea, abdominal pain, and edema, which go unreported. The management of CCB overdose includes gastrointestinal decontamination with activated charcoal and total gut lavage with polyethylene glycol along with IV fluids, vasopressors, glucagon and/or calcium infusions. ${ }^{[6]}$ Specific antidote is calcium gluconate or chloride. Other measures which can be tried include hyperinsulinemia-euglycemia therapy ${ }^{[7]}$ However, in patients with shock refractory to these therapies, anecdotal therapies have been tried with some success. These include CVVHDF without charcoal hemoperfusion, ${ }^{[8]}$ IV lipid emulsion, ${ }^{[9]}$ levosimendan, ${ }^{[10]}$ methylene blue, ${ }^{[11]}$ intra-aortic balloon pump, ${ }^{[12]}$ and extracorporeal life support. ${ }^{[13,14]}$ All these modalities were used as single rescue therapy as these patients had consumed smaller dose of CCBs and were less seriously ill than our patient.

Theoretically, hemodialysis is ineffective for removal of drugs that are highly protein bound. ${ }^{[6]}$ The shock in our patient was refractory to all other measures, which prompted us to use a combination of IV lipid emulsion, CVVHDF and charcoal hemoperfusion as a rescue therapy. Our case was unique because, to the best of our knowledge, multiple therapeutic modalities had not been combined previously. Our patient showed a dramatic response to this triple therapy.

The limitation of our case report is the absence of drug levels of amlodipine in our institution and hence the effect of IV lipid emulsion and charcoal hemoperfusion on serum concentration of amlodipine could not be ascertained.

\section{Conclusion}

Management of massive CCB overdose requires combined use of fluid resuscitation, vasopressors, calcium and glucagon infusions to improve organ perfusion. IV lipid emulsion for binding of CCB's followed by the use of extracorporeal therapies like CVVHDF with charcoal hemoperfusion for removal of CCB from circulation may be tried as rescue therapies in patients with shock refractory to standard measures.

\section{References}

1. Adams BD, Browne WT. Amlodipine overdose causes prolonged calcium channel blocker toxicity. Am J Emerg Med 1998;16:527-8.

2. Saravu K, Balasubramanian R. Near-fatal amlodipine poisoning. J Assoc Physicians India 2004;52:156-7.

3. Ghosh S, Sircar M. Calcium channel blocker overdose: Experience with amlodipine. Indian J Crit Care Med 2008;12:190-3.

4. Haria M, Wagstaff A.J. Amlodipine. A reappraisal of its pharmacological properties and therapeutic use in cardiovascular disease. Drugs 
1995;50:560-86

5. Abernethy DR. The pharmacokinetic profile of amlodipine. Am Heart J 1989;118:1100-3.

6. Kerns W $2^{\text {nd }}$. Management of beta-adrenergic blocker and calcium channel antagonist toxicity. Emerg Med Clin North Am 2007;25:309-31.

7. Shepherd G. Treatment of poisoning caused by beta-adrenergic and calcium-channel blockers. Am J Health Syst Pharm 2006;63:1828-35.

8. Pfaender M, Casetti PG, Azzolini M, Baldi ML, Valli A. Successful treatment of a massive atenolol and nifedipine overdose with CVVHDF. Minerva Anestesiol 2008;74:97-100.

9. Jeffrey G, Calvin M, Houtan S, Bryan H. Intravenous lipid emulsion for amlodipine overdose. Crit Care Med 2012;40:1215.

10. Teker MG, Ozdemir H, Saidoglu L, Erkalp K, Başaranoğlu G. Levosimendan as a rescue adjunct in amlodipine intoxication: A case report. Middle East J Anesthesiol 2010;20:869-72.

11. Jang DH, Nelson LS, Hoffman RS. Methylene blue in the treatment of refractory shock from an amlodipine overdose. Ann Emerg Med
2011;58:565-7.

12. Frierson J, Bailly D, Shultz T, Sund S, Dimas A. Refractory cardiogenic shock and complete heart block after unsuspected verapamil-SR and atenolol overdose. Clin Cardiol 1991;14:933-5.

13. Kolez J, Pietrzyk J, Januszewska K, Procelewska M, Mroczek T, Malec E. Extracorporeal life support in severe propranolol and verapamil intoxication. J Intensive Care Med 2007:22:381-5.

14. Persad EA, Raman L, Thompson MT, Sheeran PW. The use of extracorporeal life support in adolescent amlodipine overdose. Indian J Crit Care Med 2012;16:204-6.

How to cite this article: Garg SK, Goyal PK, Kumar R, Juneja D, Bhasin A, Singh O. Management of life-threatening calcium channel blocker overdose with continuous veno-venous hemodiafiltration with ch! arcoal hemoperfusion. Indian J Crit Care Med 2014;18:399-401.

Source of Support: Nil, Conflict of Interest: None declared.

\section{Staying in touch with the journal}

1) Table of Contents (TOC) email alert Receive an email alert containing the TOC when a new complete issue of the journal is made available online. To register for TOC alerts go to www.ijccm.org/signup.asp.

\section{2) RSS feeds}

Really Simple Syndication (RSS) helps you to get alerts on new publication right on your desktop without going to the journal's website. You need a software (e.g. RSSReader, Feed Demon, FeedReader, My Yahoo!, NewsGator and NewzCrawler) to get advantage of this tool. RSS feeds can also be read through FireFox or Microsoft Outlook 2007. Once any of these small (and mostly free) software is installed, add www.ijccm.org/rssfeed.asp as one of the feeds. 